\title{
Strategy to discover full-length amyloid-beta peptide ligands using high-efficiency microarray technology
}

\author{
Clelia Galati $^{* 1}$, Natalia Spinella ${ }^{1}$, Lucio Renna ${ }^{1}$, Danilo Milardi ${ }^{2}$, Francesco Attanasio ${ }^{2}$, \\ Michele Francesco Maria Sciacca ${ }^{2}$ and Corrado Bongiorno ${ }^{3}$
}

\author{
Full Research Paper \\ Address: \\ ${ }^{1}$ STMicroelectronics, Stradale Primosole, 95121, Catania, Italy, \\ ${ }^{2} \mathrm{CNR}$-Istituto di Biostrutture e Bioimmagini, Catania, Italy and \\ 3IMM-CNR, Catania, Italy \\ Email: \\ Clelia Galati* - clelia.galati@st.com \\ * Corresponding author \\ Keywords: \\ Alzheimer's disease; florescence; high sensitivity; peptide; silicon \\ oxide; TEM
}

Beilstein J. Nanotechnol. 2017, 8, 2446-2453.

doi:10.3762/bjnano.8.243

Received: 08 June 2017

Accepted: 19 October 2017

Published: 20 November 2017

Associate Editor: M. Stenzel

(C) 2017 Galati et al.; licensee Beilstein-Institut.

License and terms: see end of document.

\begin{abstract}
Although the formation of $\beta$-amyloid (A $\beta$ ) fibrils in neuronal tissues is a hallmark of Alzheimer disease (AD), small-sized A $\beta$ oligomers rather than mature fibrils have been identified as the most neurotoxic species. Therefore, the design of new inhibitors, able to prevent the aggregation of $\mathrm{A} \beta$, is believed to be a promising therapeutic approach to $\mathrm{AD}$. Unfortunately, the short-lived intermediate structures that occur in a solution along the $A \beta$ aggregation pathway escape conventional experimental investigations and there is urgent need of new tools aimed at the discovery of agents targeting monomeric $A \beta$ and blocking the early steps of amyloid aggregation. Here, we show the combination of high-efficiency slides (HESs) with peptide microarrays as a promising tool for identifying small peptides that bind A $\beta$ monomers. To this aim, HESs with two immobilized reference peptides, (i.e., KLVFF and Semax) with opposite behavior, were investigated for binding to fluorescently labeled A $\beta$ peptide. Transmission electron microscopy was used to demonstrate $A \beta$ fibrillar aggregates missing. The use of HESs was critical to ensure convenient output of the fluorescent microarrays. The resulting sensitivity, as well as the low sample consumption and the high potential for miniaturization, suggests that the proposed combination of peptide microarrays and highly efficient slides would be a very effective technology for molecule profiling in AD drug discovery.
\end{abstract}

\section{Introduction}

According to the World Health Organization (WHO), the number of people living with Alzheimer's disease (AD) worldwide is now greater than 47 million, and this number is expected to grow to 75 million by 2030. Alzheimer's disease leads to nervecell death, and scientists believe that the observed build-up of plaque between nerve cells could be the cause of cell death [1].
Two peptides, 40 and 42 amino acids long, known as $\mathrm{A} \beta 40$ and $A \beta 42$ amyloid, are the main constituents of the fibrillar plaques [2].

Although amyloid fibrils were initially considered the real causative agents of $\mathrm{AD}$, more recent works have suggested that 
small-sized $A \beta$ oligomers are the main cytotoxic species [3], and that $\mathrm{A} \beta$ monomers may even be neuroprotective [4], in line with these findings, the possibility to detect the small-sized $A \beta$ oligomers was recently demonstrated too [5]. Thus, the design of novel molecules that target $\mathrm{A} \beta$ monomers and able to prevent the formation of small toxic oligomers may be considered a promising goal of a number of therapeutic strategies under development. Thus far, a number of different compounds including Congo Red derivatives [6], antibodies [7], osmolytes [8], curcumin [9], carnosine [10], peptide $\beta$-sheet breakers [11-13], epigallocatechin-3-gallate (ECGC) [14], D-enantiomeric peptides [15], nonpeptidic $\beta$-sheet breakers [16], Sylibins [17], and metal ionophores [18], have been investigated for their potential to treat $\mathrm{AD}$ by preventing $\mathrm{A} \beta$ aggregation, but none of them could be successfully transferred into clinical practice. It is likely that the limited success of these molecules may be ascribed to our incomplete knowledge of the $A \beta$ aggregation state targeted by the ligand in the solution. In fact, studies addressing the binding of small inhibitors to the $A \beta$ monomers are challenging due to the short lifetimes of the intermediate aggregation states and the highly dynamic nature of their transition into the final fibrils $[19,20]$. Therefore, there is an urgent need for sensitive tools capable of capturing binding events even at $A \beta$ peptide concentrations at which the $A \beta$ peptide is known to be in a monomeric state.

As a proof of concept for the binding capacity of two peptides with opposite behavior was evaluated in parallel manner; a high-efficiency slide (HES) is used in place of microscope glass slides in order to obtain meaningful results. In the recent past, small molecule microarrays (SMMs) based on isocyanate-modified glass slides have been developed [21]. Several compounds immobilized on the surface were screened for binding to fluorescently-labeled A $\beta 40$. The use of HESs plays a fundamental role because the high sensitivity allows $A \beta$ peptide to be used at very low concentrations. By keeping the $A \beta$ peptide below the critical concentration at which aggregations begin to occur $[22,23]$, the study of the interaction between oligopeptides and $\mathrm{A} \beta$ peptide in monomeric form can be possible. In addition, due to the use of HESs, low concentrations of peptide are used achieving a relatively inexpensive assay.

Here, the HES is a silicon-based substrate able to act as a fluorescence amplifier. The intensity of the fluorescence is increased by exploiting the constructive interference phenomena of the electric field of light in the near-surface region [24,25] for a chosen range of frequencies. In addition, a high signal-tonoise ratio due to the low background autofluorescence of the material is obtained [26]. A high purity of the material involved, chemical inertness and stability and atomic flatness of the surface are other important features of the used system [27]. An additional advantage is the ease of implementing on it consolidated coating methods for the hosting of biomolecules.

In this work, for peptide immobilization in a microarray format, we propose one of the most common functionalization methods (an epoxysilane) although different kinds of functionalization processes can be used [28]. To validate the new platform with suitable control experiments, we used two different peptides (i.e., KLVFF and Semax), investigating their ability to bind monomeric A $\beta$. Residues encompassing the domain 16-20 of the $A \beta$ peptide may act as a self-recognition motif seeding amyloid growth. Therefore, peptides containing this sequence are supposed to interact with $\mathrm{A} \beta$ and eventually hinder its selfassembly [29]. This class of peptides was referred to as $\beta$-sheet breaker (BSB) peptides. The first example was proposed by Tjernberg, who in the mid-1990's presented the KLVFF pentapeptide (A $\beta 16-20)$ as a strategy to arrest the formation of $\beta$-amyloid fibrils, confirming that amino-acid residues located within or close to this region are important for the adoption of the correct $\beta$-sheet structure of $A \beta[30]$.

Semax is an hexapeptide (Met-Glu-His-Phe-Pro-Gly-Pro) with a sequence very similar to the $\mathrm{ACTH}(4-10)$ fragment (Met-Glu-His-Phe-Arg-Trp-Gly). Differently from the parent molecule ACTH, Semax has no hormonal activity [31]. In vitro and in vivo studies of the peptide activity have shown that Semax affects cognitive brain function with a high efficacy in the treatment of cognitive/memory disorder [32]: nootropic, neurotrophic, neuroprotective and anti-inflammatory effects, a high affinity for copper(II) ions, and a protective ability against metal-induced cell toxicity have been observed [33-36]. Hence, the role of Semax in neurodegenerative disorders can be evaluated.

Prior to assay development, $A \beta 40$ aggregation was evaluated by transmission electron microscopy (TEM) and binding conditions of the peptides under investigation were optimized on the coated silicon oxide surface. Finally, incubation tests between oligopeptides and labeled A $\beta 40$ were carried out.

\section{Results and Discussion Aggregation state of $A \beta 40$ by transmission electron microscopy}

Though in vitro A $\beta 40$ aggregates slower than the long form A $\beta 42$ [37], aggregations of $A \beta 40$ are formed which needs to be taken into account [38]. In order to rule out the presence of aggregates in the incubation solution, the aggregation state was assessed by TEM. For that purpose, a $1 \mu \mathrm{M}$ Cy3-A $\beta 40$ solution was placed onto TEM carbon grids and stored in a suitable humidity chamber for different times. Immediately after storage, the grids were then inserted in the TEM vacuum 
chamber. The high vacuum in the TEM chamber dried them completely and all of the solute species precipitated on the grid carbon layer. After storage in the humidity chamber for one hour, the standard time used for the amyloid incubation in our microarray experiments, no fibrillar structures were observed, in accordance with literature data [21]. The appearance of fibrillar structures was only observed for the longer-aged samples. Figure 1 shows the morphology of fibrils observed after two days of storage in the humidity chamber. The fibrillar structures appear with a diameter of about $5 \mathrm{~nm}$ and are morphologically analogue to the branched fibrillar form described elsewhere [39]. Figure 1B displays a more rich area of fibrils, showing the typical $5 \mathrm{~nm}$ wide component strands consistent with the ribbon aggregate morphology; inset is the magnified view of the yellow box in Figure 1B in which details of the ribbon aggregates are clearly visible.

\section{Propensity of the epoxysilane HESs to immobilize peptides}

Silanization has been widely-used as a strategy to prepare optimal protein or DNA microarrays $[25,26,40]$, the epoxide groups may bind peptide molecules through the reaction with the basic amino acid residues of the peptide. The propensity of the epoxysilane HESs to immobilize peptides was investigated by measuring the fluorescence of $1 \mu \mathrm{M}$ Cy3-A $\beta 40$ spot arrays previously assayed until the blocking step. For comparison, reference HESs properly prepared with an $\mathrm{O}_{2}$-plasma treatment have been tested. In particular, immediately after the spotting of the amyloid solution, the epoxysilane and the reference slides were inserted into a dark humidity chamber and incubated overnight at $22{ }^{\circ} \mathrm{C}$ and $95 \%$ relative humidity to immobilize the amyloid spot arrays. The slides were then blocked with BSA buffer following the standard microarray protocol (described in the Experimental section). After BSA blocking, the slides were scanned in order to check the fluorescence of the amyloid spots after the extensive washing involved in the blocking process.

As shown in Figure 2A, bright amyloid spots are observed on the functionalized slides only. The fluorescence intensity of each spot defines regular circles matched with the spotting scheme. This spot morphology results from the optimal wettability of the epoxysilane slide (see Figure S1 in Supporting Information File 1 for contact angle measurements) that prevents the spreading and coalescence of the spots. As far as
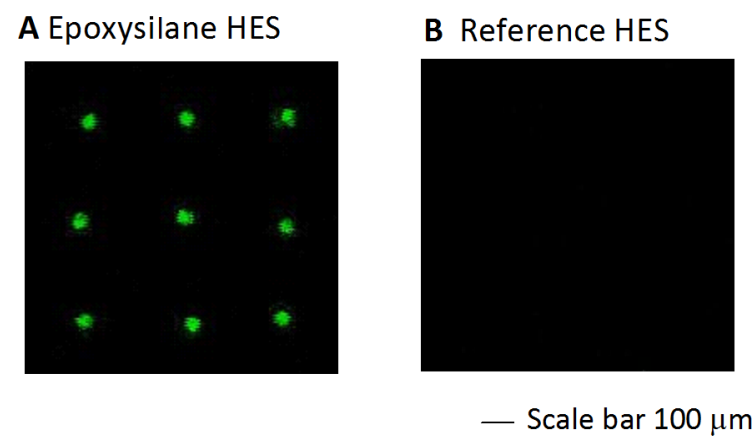

Figure 2: Ability of the epoxysilane-HES to immobilize peptides: fluorescence measurement $(60 \%$ power laser and gain) are relative to Cy3-labelled $A \beta 40$ peptides spotted on (A) an epoxysilane and (B) on an $\mathrm{O}_{2}$-plasma treated $\mathrm{HES}$ after the extensive washing involved in the BSA-blocking process.
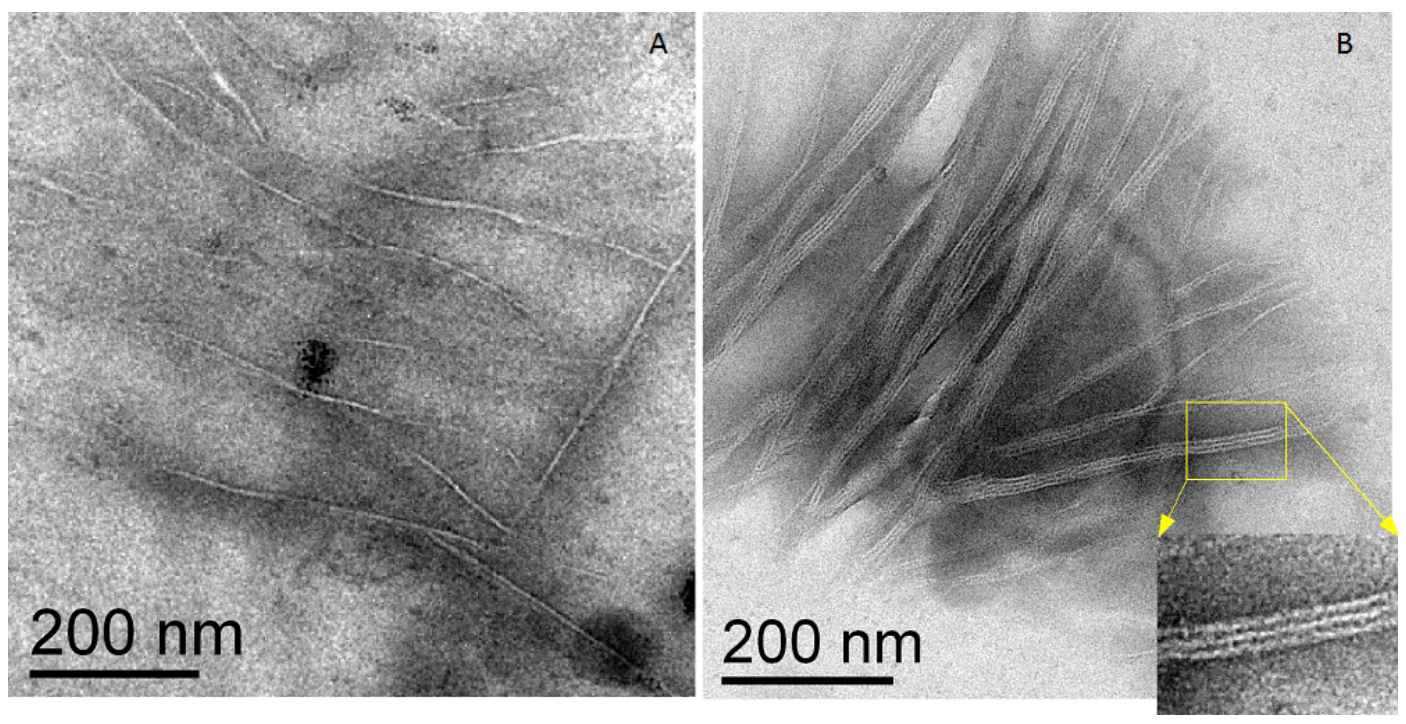

Figure 1: TEM images of $A \beta 40$ fibrils observed after two days of storage. Individual fibril and ribbon-like structures with a branched arrangement are observed in correspondence of a poor $(A)$ and rich fibrillar area $(B)$. The inset shown in $(B)$ is a magnification of a ribbon-like structure consisting of three individual fibrils. The wide of a single filament is around $5 \mathrm{~nm}$. 
reference slide is concerned, in order to minimize effects due to different wettability, stored slide with similar contact angle and very low fluorescence background were used.

The background level of the epoxysilane slide does not essentially increase after the blocking process or differ from the fluorescence background level measured on the reference HESs. This result suggests that the silanization process does not critically modify optical properties of the HESs and the interference phenomena responsible for the fluorescence enhancement may still be preserved upon silanization.

No fluorescence spots have been observed on the reference slide. In this case, the blocking-washing step was effective to fully remove the full-length amyloid spots. After the $\mathrm{O}_{2}$-plasma treatment, the surface of the un-epoxysilane slides may likely be rich in $\mathrm{Si}-\mathrm{OH}$ groups that can be reactive against several environmental species, e.g., water; the silanization process may instead generate a certain number of reactive epoxide groups, randomly oriented at the silicon surface, which may react with the basic amino groups of the full-length amyloid peptide and therefore immobilize the peptide at the silicon surface. The same behavior can be assumed for shorter peptides.

\section{Test of amyloid-beta 1-40 binding by peptide ligands on HES}

The synthesized pentapeptide KLVFF and a commercial therapeutic heptapeptide, Semax, have been assayed to investigate their ability to bind full-length $A \beta 40$ peptides. KLVFF was chosen as reference for its ability to bind to specific regions of the full-length $A \beta$ peptide. This peptide, known as $\beta$-sheet breaker, has been specifically designed to inhibit the formation of fibrils; the sequence KLVFF, corresponding to the A $\beta$ 16-20, was identified to bind full-length $A \beta$ and to prevent its fibrillation [30]. Semax was chosen for its different behavior (as will be discussed below).

The peptides were tested, as amyloid ligands, using the Cy3labeled A $\beta 40$ conjugate for fluorescence detection. As expected, after the immobilization of the unlabeled peptides only very weak signals (Figure S2A, Supporting Information File 1) were detected, deriving from the light scattering of salts contained in the phosphate buffer used to prepare the peptide spotting solution, and no bright spots were detected after the blocking step (Figure S2B, Supporting Information File 1). These fluorescence measurements suggest that the washing operations were effective to remove the buffer salts from the epoxysilane surface. However, because of the expected behavior similar to amyloid peptides (as shown in Figure 2), the unlabeled peptides were not removed. Figure 3 reports the incubation data. The fluorescent images clearly show the different propensity of the peptides under investigation to bind to the full-length $A \beta 40$. Bright Cy3-A $\beta 40$ spots were detected in the KLVFF spot array (Figure $3 \mathrm{~A}$ ) and black spots were measured on Semax (Figure 3B). In order to emphasize the different behavior of the two peptides, the florescence images were acquired with different laser and gain conditions. For incubated KLVFF spots, a lower laser power than for Semax was used. Otherwise, saturation of the detector would have been reached, which is not useful for quantitative assessments.

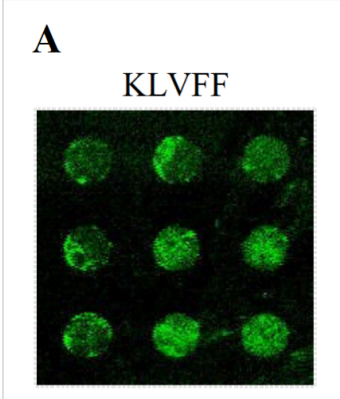

B

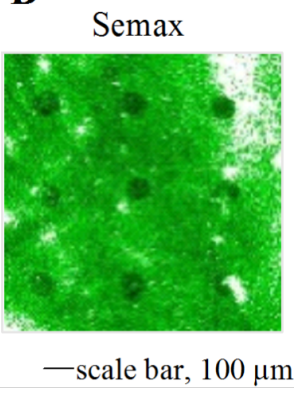

Figure 3: (A) KLVFF and (B) Semax spot arrays on an epoxysilanecoated HES after amyloid incubation. The fluorescence measurements were performed by operating at an optimized condition for laser power and gain (60\% laser power and gain for KLVFF and $100 \%$ laser power and gain for Semax).

In accordance with the previous work [24], the positive binding interaction between the KLVFF spots and the Cy3-A $\beta 40$ solution occurs, giving rise to the appearance of bright amyloid spots for the KLVFF spot array. Conversely, for the Semax peptide, the formation of black spots, was observed. This is due to the "blocking effect" phenomenom, likely deriving from an anti-bonding interaction between Semax spots and the A $\beta 40$. In this case, the amyloid preferentially interacts with the blocked epoxysilane surface rather than binding to the Semax spots. This suggests a poor ability of Semax to interact with the $A \beta$ peptide and is consistent with the absence of any anti-aggregating activity of Semax monitored by Th-T fluorescence assays (Figure 4).

Finally, to assess the sensitivity of the method, a quantitative evaluation was carried out on the coated HES. The experimental conditions of the assay are detailed in Supporting Information File 1. Briefly, solutions of known concentrations ranging from 0.01 to $1 \mu \mathrm{M}$ of Cy3-A $\beta 40$ were dispensed on the functionalized HSE (Figure S3, Supporting Information File 1). The calibration curve of the fluorescence intensity as a function of the amyloid concentration is reported in Figure S4 (Supporting Information File 1). A value of ca. $10^{3}$ amyloid molecules captured per square micrometer was achieved. In order to find potential improvements of method, and to determine the limits 


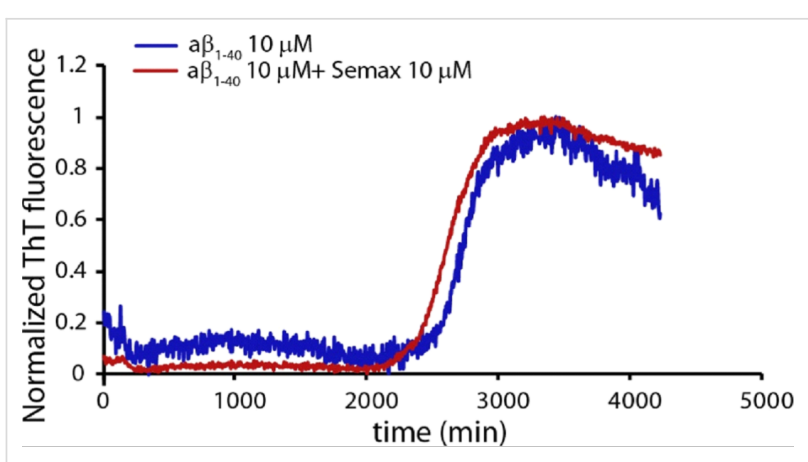

Figure 4: Amyloid fibril growth detected by Th-T fluorescence as a function of the time; $10 \mu \mathrm{M} A \beta 40$ (blue curve), $A \beta 40$ in presence of equimolar amount of Semax (red curve).

of detection (LOD), a scanarray acquisition of the calibration slide was acquired at high laser power and high photomultiplier gain (Figure S4A, Supporting Information File 1). Under these conditions the highest spotted concentrations are fully saturated. At a concentration of $0.01 \mu \mathrm{M}$ slight saturation occurs, allowing to evaluate the LOD by measuring signal and background over 16 spots and evaluating the signal corresponding to three times the average standard deviation of the background. The results show an improvements of the LOD of more than two orders of magnitude. The obtained results support the employment of HES as effective method for improving the sensitivity of microarrays (small molecule, peptide, and antibody) for multiplex detection. In this study, the HES platform has exhibited a high usefulness for studying the behavior of peptides aimed to identify potential therapeutics for Alzheimer's disease.

\section{Conclusion}

Binding assays have been performed in a microarray format by using highly efficient slides. This highly sensitive optic system has important features: very high purity of the material involved, chemical inertness and stability, and atomic flatness of the surface. Additional advantages of this substrate are the easy implementation of consolidated coating methods for the hosting of biomolecules and its simple structure which allows a fabrication with high reproducibility.

In particular, the ability of two different peptides to bind fulllength $A \beta$ peptides has simultaneously been studied, using concentrations in a range in which the $A \beta$ peptide is known to be in a monomeric state. Expected results were obtained indicating that the explored platform can be very useful in the rational drug design for $\mathrm{AD}$.

In the near future, as the effect of environmental factors, such as the presence of small molecules and metal ions, and related methods such as static or in-flow incubations, play a significant role, we shall evaluate these effects and in parallel manner. A novel microfluidic screening system including the high efficiency substrates [41] for very sensitive analyses with low consumption of reagents and short measuring times is under investigation in our laboratory.

\section{Experimental Chemicals}

Phosphate-buffered saline, hydrogen peroxide (29\%), ammonium hydroxide (25\%), hydrochloric acid (37\%), methanol, dimethyl sulfoxide (DMSO), anhydrous toluene and 3-glycidyloxypropyltrimethoxysilane (GOPs) were acquired from SigmaAldrich. Bovine serum albumin (BSA), IgG-free and proteasefree was acquired from Jackson ImmunoResearch Laboratories (West Grove, PA, USA). Cyanine3-labeled human amyloidbeta 1-40 (Cy3-A $\beta 40)$, was acquired from Phoenix Pharmaceuticals.

\section{Preparation of peptides}

The KLVFF peptide was kindly gifted by Dr. G. Pappalardo. As described in [42] this peptide was assembled using the microwave-assisted solid-phase peptide synthesis strategy on a Liberty Peptide Synthesiser. All Fmoc-amino acids were introduced according to the TBTU/HOBT/DIEA activation method, as reported elsewhere [11]. Semax was purchased from Caslo, with a purity of $98 \%$. To remove any pre-existing aggregated form of $A \beta 40$, samples were subjected to a disaggregating procedure before carrying out each experiment. The following protocol was applied: The samples were dissolved in 1,1,1,3,3,3-hexafluoro-2-propanol (HFIP) at a concentration of $1 \mathrm{mg} / \mathrm{mL}$ and incubated at $37^{\circ} \mathrm{C}$ for $1 \mathrm{~h}$. HFIP was removed by gentle streaming of argon, the peptide film was dissolved again in $1 \mathrm{~mL}$ HFIP, loaded on the plate and frozen at $-30{ }^{\circ} \mathrm{C}$ for $5 \mathrm{~h}$, then lyophilized overnight. The lyophilized samples on the plate were then dissolved in $10 \mathrm{mM}$ phosphate buffer $\mathrm{pH} 7.2$ to a concentration of $10 \mu \mathrm{M}$.

\section{Fabrication of HESs}

HESs were prepared by exploiting the highly controlled materials and technologies conventionally used for the construction of microelectronics devices. The detection sensitivity is essentially determined by the signal-to-noise $(\mathrm{S} / \mathrm{N})$ ratio. A simple approach to increasing the $\mathrm{S} / \mathrm{N}$ ratio involves the use of low-fluorescence materials as substrates. High-purity substrates may be obtained only by starting from reagents with high purity under highly controlled reaction conditions. This is the rule of silicon technology, in which(100) single-crystal 99.999999999\% pure silicon is used as the starting material. After standard cleaning, etching in diluted HF (aq), and rinsing in deionized water, single crystalline, Czochralski grown, silicon(100) slices were mounted in a conventional furnace operating at atmospheric pressure. Thermal oxidation was per- 
formed at a controlled rate in order to reproducibly grow layers of silicon oxide of a defined thickness. Thermal growth allows high-quality $\mathrm{SiO}_{2}$ films to be obtained with very low auto-fluorescence and very low contamination. The wafers were then cut in pieces to the exact dimensions of conventional microscope slides. Figure 5 shows a highly schematic functionalized high efficiency slide including a sketch of the site of incubation between the spotted peptides and labeled $A \beta 40$.

\section{Coating of HESs with GOPs}

HESs were pretreated with an oxidant solution $\left(\mathrm{H}_{2} \mathrm{O} / \mathrm{NH}_{4} \mathrm{OH} /\right.$ $\left.\mathrm{H}_{2} \mathrm{O}_{2}, 5: 1: 1\right)$ for $1 \mathrm{~min}$ at $80{ }^{\circ} \mathrm{C}$, rinsed with deionized water, immersed in a methanolic solution $\left(\mathrm{CH}_{3} \mathrm{OH} / \mathrm{HCl}, 4: 1\right)$ for $10 \mathrm{~min}$ at room temperature, rinsed with water, and dried under a nitrogen flow. Next, the slides were immersed in a solution of GOPs, 1:10 in anhydrous toluene, for $4 \mathrm{~h}$ at room temperature. The silanization process was performed in a glove box (MB10 Compact, Braun) that maintained a nitrogen atmosphere with levels of less than $1 \mathrm{ppm}$ of oxygen and humidity. Epoxysilane slides were rinsed and dried in a vacuum chamber and stored under vacuum conditions until the microarray experiments.

Water wettability of the functionalized surface was evaluated by contact angle measurements. Analysis was conducted on the dried slide immediately after the silanization process using a CAM KSV instrument operating in static mode and located in a class-1000 clean room. Drops of Millipore water were dispensed with a volume of $1 \mu \mathrm{L}$ on at least five representative areas of the epoxysilane slide. The contact angle was then evaluated using the KSV controller instrument software and a medium value of $(50 \pm 1)^{\circ}$ was obtained (Figure S1, Supporting Information File 1).

To test the propensity of the silanizated surface to immobilize peptides, reference silicon slides were properly prepared. Oxygen-plasma treatment was utilized to remove surface contaminations. This cleaning processing is useful to obtain slides with low fluorescence background, becoming a mandatory path when no wet cleaning protocol can be applied, such as in innovative integrated technologies $[41,43]$.
The $\mathrm{O}_{2}$-plasma cleaning was performed using the plasma etching system, Sentech 591, using $60 \mathrm{sccm}$ of oxygen fluxing for $2 \mathrm{~min}$. The resulting epoxysilane coating provide a proper surface for the immobilization of peptides in a microarray format. Moreover, due to the low fluorescence background, which does not significantly differ from the background level of the reference slide (i.e., the $\mathrm{O}_{2}$-plasma treated silicon slide), they are suitable to be used as substrates for fluorescence microarray assays.

\section{Aggregation states of the $A \beta 40$ by TEM}

Aliquots of $3 \mu \mathrm{L}$ of the $1 \mu \mathrm{M}$ Cy $3-\mathrm{A} \beta 40$ solution were dispensed onto carbon-coated copper grids for electron microscopy (Cy3-A $\beta 40$ conjugate was dissolved in a saline phosphate buffer containing $10 \mathrm{vol} \%$ of DMSO, $0.01 \mathrm{M}$ Phosphate, $0.154 \mathrm{M}$ sodium chloride, $\mathrm{pH}$ 7.4). To replicate the experimental conditions involved in a typical peptide microarray assay performed in this work, electron microscopy grids after amyloid dispensing were stored for at least $1 \mathrm{~h}$, the time used for the incubation of the peptide spot arrays with the Cy3-A 340 solution, as well as for longer times (up to $48 \mathrm{~h}$ ). To avoid the drying of the amyloid solution dispensed on the grids, they have been stored in a humidity chamber that was provided with a constant-humidity environment at a controlled temperature ( $22{ }^{\circ} \mathrm{C}$ and $95 \%$ relative humidity, $\mathrm{RH}$ ). The physical state of the amyloid peptides was then tested by TEM. TEM analysis was performed with a Jeol JEM 2010 electron microscope operating at $200 \mathrm{kV}$ accelerating voltage.

\section{Preparation of peptide microarray}

KLVFF and Semax peptides were dissolved in phosphate buffer at a concentration of $1 \mathrm{mg} / \mathrm{mL}$ and aliquots were stored at $-80^{\circ} \mathrm{C}$ until use. Cy3-A $\beta 40$ conjugate was dissolved in a saline phosphate buffer containing $10 \mathrm{vol} \%$ of DMSO (0.01 M Phosphate, $0.154 \mathrm{M}$ sodium chloride, $\mathrm{pH}$ 7.4) at a concentration of $1 \mu \mathrm{M}$ in accordance with the producer specification and stored at $-80{ }^{\circ} \mathrm{C}$ until use.

KLVFF, Semax peptide solutions and Cy3-A $\beta 40$ were patterned on epoxysilane HESs using a PerkinElmer Piezorray non-con-

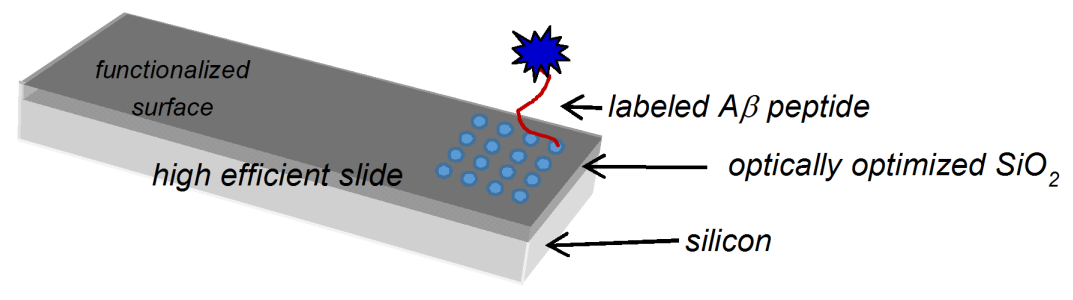

Figure 5: HES with a sketch of incubation test site. The peptide array is represented by blue dots. 
tact microarraying system. The volume of the spotted drops was $333 \mathrm{pL} \pm 5 \%$. After dispensing, all slides were placed in a humidity chamber at $22{ }^{\circ} \mathrm{C}$ and $95 \% \mathrm{RH}$ overnight. Spotted slides were then scanned with a PerkinElmer Scanarray express laser scanner apparatus. The slides were then blocked with $1 \%$ $(\mathrm{w} / \mathrm{v})$ BSA in phosphate buffer for $1 \mathrm{~h}$, washed three times under stirring with phosphate buffer for $2 \mathrm{~min}$, and finally washed with water for $10 \mathrm{~min}$. For the $\mathrm{A} \beta 40$ incubation test, the blocked slides were incubated with the $1 \mu \mathrm{M} \mathrm{Cy} 3-\mathrm{A} \beta 40$ solution in a humidity chamber at $22{ }^{\circ} \mathrm{C}$ and $95 \% \mathrm{RH}$. After $1 \mathrm{~h}$, the incubation was stopped with the phosphate washing and the final water washing. The dried slides were finally scanned for the fluorescence measurements.

\section{Th-T fluorescence measurements}

The fluorescence emission spectra of Th-T undergoes a red shift upon incorporation into $\beta$-sheet amyloid structures. An aggregation assay was performed on a VarioSkan Flash from Thermo Scientific fluorescence 96-well plate reader, programmed to agitate the plate for $30 \mathrm{~s}$ before measuring fluorescence emission. Readings were taken every $10 \mathrm{~min}$ over a range of $4200 \mathrm{~min}$. To minimize evaporation effects, the wells were sealed with a transparent heat-resistant plastic film. Fluorescence excitation was at $440 \mathrm{~nm}$ and emission detected at $480 \mathrm{~nm}$. To minimize errors during sample preparation, we freeze-dried the $10 \mu \mathrm{M} A \beta 40$ solutions directly in the well plate. The Th-T experiments were carried out at $\mathrm{pH} 7.2$, at $37{ }^{\circ} \mathrm{C}$ and in $10 \mathrm{mM}$ phosphate buffer and replicated three times. The Semax concentration was $10 \mu \mathrm{M}$. The Th-T concentration was $20 \mu \mathrm{M}$.

\section{Supporting Information}

Supporting Information includes additional data relative to the characterization of material surface, quantitative evaluations, and a study of a possible interaction between the anchored-amyloid and amyloid-target.

\section{Supporting Information File 1}

Additional figures, quantitative evaluations and further experimental data.

[http://www.beilstein-journals.org/bjnano/content/ supplementary/2190-4286-8-243-S1.pdf]

\section{Acknowledgements}

We are grateful to STMicroelectronics' R\&D Pilot Line for manufacturing the HES. We also thank Dr. G. Pappalardo for the gift of the peptides and the helpful discussions. This work was financially supported by the Italian MiUR programs FIRBMERIT RBNE08HWLZ and PRIN 20157WZM8A.

\section{References}

1. Hardy, J. Neurobiol. Aging 2002, 23, 1073-1074. doi:10.1016/S0197-4580(02)00042-8

2. Kang, J.; Lemaire, H.-G.; Unterbeck, A.; Salbaum, J. M.; Masters, C. L.; Grzeschik, K.-H.; Multhaup, G.; Beyreuther, K.; Müller-Hill, B. Nature 1987, 325, 733-736. doi:10.1038/325733a0

3. Haass, C.; Selkoe, D. J. Nat. Rev. Mol. Cell Biol. 2007, 8, 101-112. doi:10.1038/nrm2101

4. Giuffrida, M. L.; Caraci, F.; Pignataro, B.; Cataldo, S.; De Bona, P.; Bruno, V.; Molinaro, G.; Pappalardo, G.; Messina, A.; Palmigiano, A.; Garozzo, D.; Nicoletti, F.; Rizzarelli, E.; Copani, A. J. Neurosci. 2009, 29, 10582-10587. doi:10.1523/jneurosci.1736-09.2009

5. Wennmalm, S.; Chmyrov, V.; Widengren, J.; Tjernberg, L. Anal. Chem. 2015, 87, 11700-11705. doi:10.1021/acs.analchem.5b02630

6. Frid, P.; Anisimov, S. V.; Popovic, N. Brain Res. Rev. 2007, 53, 135-160. doi:10.1016/j.brainresrev.2006.08.001

7. Solomon, B. Curr. Opin. Invest. Drugs (BioMed Cent.) 2007, 8, 519-524.

8. Yang, D.-S.; Yip, C. M.; Huang, T. H. J.; Chakrabartty, A.; Fraser, P. E. J. Biol. Chem. 1999, 274, 32970-32974. doi:10.1074/jbc.274.46.32970

9. Begum, A. N.; Jones, M. R.; Lim, G. P.; Morihara, T.; Kim, P.; Heath, D. D.; Rock, C. L.; Pruitt, M. A.; Yang, F.; Hudspeth, B.; Hu, S.; Faull, K. F.; Teter, B.; Cole, G. M.; Frautschy, S. A. J. Pharmacol. Exp. Ther. 2008, 326, 196-208. doi:10.1124/jpet.108.137455

10. Attanasio, F.; Convertino, M.; Magno, A.; Caflisch, A.; Corazza, A.; Haridas, H.; Esposito, G.; Cataldo, S.; Pignataro, B.; Milardi, D.; Rizzarelli, E. ChemBioChem 2013, 14, 583-592. doi:10.1002/cbic.201200704

11. De Bona, P.; Giuffrida, M. L.; Caraci, F.; Copani, A.; Pignataro, B.; Attanasio, F.; Cataldo, S.; Pappalardo, G.; Rizzarelli, E. J. Pept. Sci. 2009, 15, 220-228. doi:10.1002/psc.1109

12. Soto, C.; Sigurdsson, E. M.; Morelli, L.; Kumar, R. A.; Castaño, E. M.; Frangione, B. Nat. Med. 1998, 4, 822-826. doi:10.1038/nm0798-822

13. Soto, P.; Griffin, M. A.; Shea, J.-E. Biophys. J. 2007, 93, 3015-3025. doi:10.1529/biophysj.107.112086

14. Bieschke, J.; Russ, J.; Friedrich, R. P.; Ehrnhoefer, D. E.; Wobst, H.; Neugebauer, K.; Wanker, E. E. Proc. Natl. Acad. Sci. U. S. A. 2010, 107, 7710-7715. doi:10.1073/pnas.0910723107

15. Brener, O.; Dunkelmann, T.; Gremer, L.; van Groen, T.; Mirecka, E. A.; Kadish, I.; Willuweit, A.; Kutzsche, J.; Jürgens, D.; Rudolph, S.; Tusche, M.; Bongen, P.; Pietruszka, J.; Oesterhelt, F.; Langen, K.-J.; Demuth, H.-U.; Janssen, A.; Hoyer, W.; Funke, S. A.; Nagel-Steger, L.; Willbold, D. Sci. Rep. 2015, 5, 13222. doi:10.1038/srep13222

16. Rzepecki, P.; Nagel-Steger, L.; Feuerstein, S.; Linne, U.; Molt, O.; Zadmard, R.; Aschermann, K.; Wehner, M.; Schrader, T.; Riesner, D. J. Biol. Chem. 2004, 279, 47497-47505. doi:10.1074/jbc.M405914200

17. Sciacca, M. F. M.; Romanucci, V.; Zarrelli, A.; Monaco, I.; Lolicato, F.; Spinella, N.; Galati, C.; Grasso, G.; D’Urso, L.; Romeo, M.; Diomede, L.; Salmona, M.; Bongiorno, C.; Di Fabio, G.; La Rosa, C.; Milardi, D. ACS Chem. Neurosci. 2017, 8, 1767-1778. doi:10.1021/acschemneuro.7b00110

18. Grasso, G.; Santoro, A. M.; Lanza, V.; Sbardella, D.; Tundo, G. R.; Ciaccio, C.; Marini, S.; Coletta, M.; Milardi, D. Coord. Chem. Rev. 2017, 347, 1-22. doi:10.1016/j.ccr.2017.06.004

19. Pannuzzo, M.; Milardi, D.; Raudino, A.; Karttunen, M.; La Rosa, C. Phys. Chem. Chem. Phys. 2013, 15, 8940-8951. doi:10.1039/c3cp44539a

20. Pannuzzo, M.; Raudino, A.; Milardi, D.; La Rosa, C.; Karttunen, M. Sci. Rep. 2013, 3, 2781. doi:10.1038/srep02781 
21. Chen, J.; Armstrong, A. H.; Koehler, A. N.; Hecht, M. H. J. Am. Chem. Soc. 2010, 132, 17015-17022. doi:10.1021/ja107552s

22. Harper, J. D.; Lansbury, P. T. Annu. Rev. Biochem. 1997, 66, 385-407. doi:10.1146/annurev.biochem.66.1.385

23. O'Nuallain, B.; Shivaprasad, S.; Kheterpal, I.; Wetzel, R. Biochemistry 2005, 44, 12709-12718. doi:10.1021/bi050927h

24. Volle, J.-N.; Chambon, G.; Sayah, A.; Reymond, C.; Fasel, N.; Gijs, M. A. M. Biosens. Bioelectron. 2003, 19, 457-464. doi:10.1016/s0956-5663(03)00201-x

25. Bras, M.; Dugas, V.; Bessueille, F.; Cloarec, J. P.; Martin, J. R.; Cabrera, M.; Chauvet, J. P.; Souteyrand, E.; Garrigues, M. Biosens. Bioelectron. 2004, 20, 797-806.

26. Arrabito, G.; Galati, C.; Castellano, S.; Pignataro, B. Lab Chip 2013, 13, 68-72. doi:10.1039/c2lc40948h

27. Cretich, M.; di Carlo, G.; Longhi, R.; Gotti, C.; Spinella, N.; Coffa, S.; Galati, C.; Renna, L.; Chiari, M. Anal. Chem. 2009, 81, 5197-5203. doi:10.1021/ac900658c

28. Cretich, M.; Galati, C.; Renna, L.; Condorelli, G. G.; Gagni, P.; Chiari, M. Sens. Actuators, B 2014, 192, 15-22. doi:10.1016/j.snb.2013.09.119

29. Chalifour, R. J.; McLaughlin, R. W.; Lavoie, L.; Morissette, C.; Tremblay, N.; Boulé, M.; Sarazin, P.; Stéa, D.; Lacombe, D.; Tremblay, P.; Gervais, F. J. Biol. Chem. 2003, 278, 34874-34881. doi:10.1074/jbc.M212694200

30. Tjernberg, L. O.; Näslund, J.; Lindqvist, F.; Johansson, J.; Karlström, A. R.; Thyberg, J.; Terenius, L.; Nordstedt, C. J. Biol. Chem. 1996, 271, 8545-8548. doi:10.1074/jbc.271.15.8545

31. Rzepecki, P.; Steger, L. N.; Feuerstein, S.; Linne, U.; Molt, O.; Zadmard, R.; Aschermann, K.; Wehner, M.; Schrader, T.; Riesner, D. J. Neurochem. 2006, 97, 82-86.

32. Ashmarin, I. P.; Nezavibatko, V. N.; Myasoedov, N. F.; Kamenskii, A. A.; Grivennikov, I. A.; Ponomareva-Stepnaya, M. A.; Andreeva, L. A.; Kaplan, A. Y.; Kosheleva, V. B.; Ryasina, T. V. Zh. Vyssh. Nervn. Deyat. im. I. P. Pavlova 1997, 47, 420-430.

33. Bashkatova, V. G.; Koshelev, V. B.; Fadyukova, O. E.; Alexeev, A. A.; Vanin, A. F.; Rayevsky, K. S.; Ashmarin, I. P.; Armstrong, D. M. Brain Res. 2001, 894, 145-149. doi:10.1016/S0006-8993(00)03324-2

34. Potaman, V. N.; Antonova, L. V.; Dubynin, V. A.; Zaitzev, D. A.; Kamensky, A. A.; Myasoedov, N. F.; Nezavibatko, V. N. Neurosci. Lett. 1991, 127, 133-136. doi:10.1016/0304-3940(91)90912-d

35. Storozhevykh, T. P.; Tukhbatova, G. R.; Senilova, Ya. E.; Pinelis, V. G.; Andreeva, L. A.; Myasoyedov, N. F. Bull. Exp. Biol. Med. 2007, 143, 601-604. doi:10.1007/s10517-007-0192-x

36. Tabbì, G.; Magrì, A.; Giuffrida, A.; Lanza, V.; Pappalardo, G.; Naletova, I.; Nicoletti, V. G.; Attanasio, F.; Rizzarelli, E. J. Inorg. Biochem. 2015, 142, 39-46.

37. Seilheimer, B.; Bohrmann, B.; Bondolfi, L.; Müller, F.; Stüber, D.; Döbeli, H. J. Struct. Biol. 1997, 119, 59-71. doi:10.1006/jsbi.1997.3859

38. Hansson, O.; Zetterberg, H.; Peder, B. P.; Andreasson, U.; Londos, E.; Minthon, L.; Blennow, K. Dementia Geriatr. Cognit. Disord. 2007, 23, 316-320. doi:10.1159/000100926

39. Goldsbury, C. S.; Wirtz, S.; Müller, S. A.; Sunderji, S.; Wicki, P.; Aebi, U.; Frey, P. J. Struct. Biol. 2000, 130, 217-231. doi:10.1006/jsbi.2000.4259

40. Morales-Narváez, E.; Montón, H.; Fomicheva, A.; Merkoçi, A. Anal. Chem. 2012, 84, 6821-6827. doi:10.1021/ac301369e

41. Renna, L.; Galati, C.; Spinella, N. M. R.; Coffa, S. Optically Accessible Microfluidic Diagnostic Device. U.S. Patent US020110291026A1, Dec $1,2011$.
42. Sinopoli, A.; Magrì, A.; Milardi, D.; Pappalardo, M.; Pucci, P. Flagiello, A.; Titman, J. J.; Nicoletti, V. G.; Caruso, G.; Pappalardo, G.; Grasso, G. Metallomics 2014, 6, 1841-1852. doi:10.1039/c4mt00130c 43. Renna, L.; Galati, C.; Spinella, N.; Mazzillo, M.; Abbisso, S.; Fallica, P. G. Sens. Actuators, B 2015, 209, 1011-1014. doi:10.1016/j.snb.2014.12.014

\section{License and Terms}

This is an Open Access article under the terms of the Creative Commons Attribution License (http://creativecommons.org/licenses/by/4.0), which permits unrestricted use, distribution, and reproduction in any medium, provided the original work is properly cited.

The license is subject to the Beilstein Journal of Nanotechnology terms and conditions: (http://www.beilstein-journals.org/bjnano)

The definitive version of this article is the electronic one which can be found at: $\underline{\text { doi:10.3762/bjnano. } 8.243}$ 